\title{
Retrospective cohort study of rough-surface titanium implants with at least 25 years' function
}

\author{
Tadashi Horikawa ${ }^{1 \dagger}$, Tetsurou Odatsu ${ }^{2 * \dagger}$ (D), Takatoshi Itoh ${ }^{1}$, Yoshiki Soejima ${ }^{1}$, Hutoshi Morinaga ${ }^{1}$, Naruyoshi Abe ${ }^{1}$, \\ Naoyuki Tsuchiya', Toshikazu lijima ${ }^{1}$ and Takashi Sawase ${ }^{1,2}$
}

\begin{abstract}
Background: The longitudinal clinical outcomes over decades contribute to know potential factors leading to implant failure or complications and help in the decision of treatment alternatives.

Methods: The cases of all patients who received dental implants treated with titanium plasma-sprayed surfaces and whose prostheses were set in the period 1984-1990 at seven private practices were retrospectively analyzed. The cumulative survival rate, the cumulative incidence of peri-implantitis, and the complication-free prosthesis rate were calculated with Kaplan-Meier survival curves, and the factors' influence on implant survival rate and the incidence of peri-implantitis were determined by a single factor in univariate analyses and multivariate analyses.

Results: A total of 223 implants and 106 prostheses were applied to 92 patients, and approx. 62\% of the implants and patients dropped out over the 25 years following their treatment. The cumulative survival rates of the implants at 10, 15, and 25 years were 97.4, 95.4, and 89.8\%, respectively. A significant difference was observed in the implant position. The cumulative incidences of peri-implantitis at 10, 15, and 25 years were 15.3, 21.0, and 27.9\%, respectively. Significant differences were observed in the gender, implant type, and width of keratinized mucosa around the implant. The cumulative survival rates of mechanical complication-free prostheses at 10,15, and 25 years were 74.9, 68.8, and $56.4 \%$, respectively. The difference in the type of prosthesis resulted in significant differences.

Conclusions: The high rate of dropout during follow-up indicates the difficulty of determining long-term (> 25 years) prognoses. The gender, location, and width of keratinized mucosa affected the development of peri-implantitis, resulting in late failures. Implant-supported overdentures were frequently repaired. Tooth implant-supported prostheses are not recommended for long-term survival.
\end{abstract}

Keywords: Dental implants, Implant-supported prosthesis, Long-term survival, Titanium plasma-sprayed surface

\section{Background}

Dental implant treatment based on the concept of osseointegration [1] is now a widely accepted restorative treatment for fully and partially edentulous patients. In the earliest days of the use of osseointegrated implants, two different topographies were applied on the implant surfaces: a machined minimally rough titanium surface such as the Brånemark system and a rough microporous

\footnotetext{
* Correspondence: odatsu@nagasaki-u.ac.jp

${ }^{\dagger}$ Equal contributors

2Department of Applied Prosthodontics, Graduate School of Biomedical Sciences, Nagasaki University, 1-7-1 Sakamoto, Nagasaki 852-8588, Japan Full list of author information is available at the end of the article
}

titanium plasma-sprayed surface such as the ITI system [2]. In clinical studies, the long-term (i.e., up to 20 years) survival rate of Brånemark-system implants was in the range of $80-99 \%$ [3-5] and that with ITI-system implants was $88-96 \%$ [6, 7].

Despite the high survival rates, implant-supported restorations are still subject to biological and mechanical complications. The focus in dental implant treatments has shifted from implant survival to (1) implant success, (2) peri-implant infection, and (3) long-term outcomes of prostheses. Since the increasing human life expectancy and most of the patients who undergo implant treatment are middle-aged (approx. 40-60 years old) [8, 9], the 
Table 1 Age and gender distributions ( $n=92)$

\begin{tabular}{llll}
\hline Age/gender & Male & Female & Total \\
\hline $20-29$ & 3 & 1 & 4 \\
$30-39$ & 2 & 7 & 9 \\
$40-49$ & 8 & 14 & 22 \\
$50-59$ & 8 & 18 & 26 \\
$60-69$ & 15 & 13 & 28 \\
$70-79$ & 2 & 1 & 3 \\
Total & 38 & 54 & 92 \\
\hline
\end{tabular}

determination of these longitudinal clinical outcomes over decades will contribute to the evaluation of treatment alternatives.

The aim of this retrospective study was not only to evaluate the long-term outcomes of solid-screw implants with a titanium plasma-sprayed (TPS) surface but also to assess the survival rates associated with the biological and mechanical complications.

\section{Methods}

\section{Study design}

This retrospective observational study was approved by the ethical committee of Nagasaki University (No. 1512). The cases of all of the patients who underwent dental implant treatment with a TPS-surfaced solid-screw implant and whose prosthesis was set in the years 19841990 at seven private practices were analyzed. All inserted implants were either a TPS-type (TPS-type, Institute Straumann, Basel, Switzerland) implant or a BONEFIT $45^{\circ}$ shoulder-type (S-type, Institute Straumann) implant. We identified a total of 223 implants inserted into 92 patients.

\section{Medical record assessment}

Medical records were reviewed, and the patient-related parameters of age, gender, smoking habit, the date of

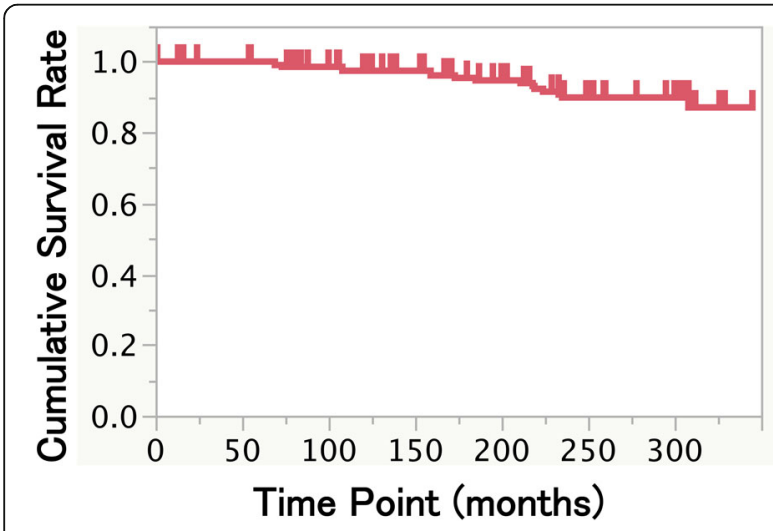

Fig. 1 Kaplan-Meier cumulative survival rate at 10, 15, and 25 years after the prosthesis setting
Table 2 Distribution of implants in situ $(n=223)$

\begin{tabular}{lllllllll}
\hline Position & 1 & 2 & 3 & 4 & 5 & 6 & 7 & Total \\
\hline Maxilla & 0 & 0 & 2 & 6 & 6 & 8 & 2 & 24 \\
Mandible & 7 & 32 & 8 & 30 & 20 & 59 & 43 & 199 \\
\hline
\end{tabular}

implant surgery, and the date of the prosthesis setting were collected. The information of implant (length, diameter, type), site of implantation, width of keratinized mucosa, and additional pre- and/or post-implant surgery (i.e., bone augmentation, soft tissue management) was also collected. The types of prostheses were classified into implant-supported fixed prostheses, tooth implantsupported fixed prostheses, and implant-supported overdentures.

The endpoint of this study was set at December 31, 2015. Episodes of implant failure, biological complication (i.e., peri-implantitis with suppuration), and mechanical complications (i.e., component or laboratory-fabricated suprastructure's failure) were recorded.

\section{Statistical analysis}

JMP Pro software (ver. 11.2.0, SAS, Cary, NC, USA) was used for the statistical data analyses. The cumulative implant survival rate, the cumulative incidence of periimplantitis, and the cumulative "complication-free" survival rate of implant-supported restorations were analyzed using the Kaplan-Meier survival estimator method. The cumulative "mechanical complication-free" survival rate of implant-supported restorations was estimated by a restoration-based analysis. The influence of the following variables on the implant survival rate and the incidence of peri-implantitis were determined by a single factor in univariate analyses (Kaplan-Meier) and multivariate analyses (Cox proportional hazards regression analysis): patient gender, smoking habit, implant type (S-type or TPS-type), implant position (three categories: maxilla, anterior mandible, posterior mandible), presence of additional soft tissue management (i.e., free-gingival graft, vestibular extension, and frenectomy), and the width of keratinized mucosa around implant (> $2 \mathrm{~mm}$ ). The influence of patient gender and type of prosthesis on the complication-free survival rate of implant-supported restorations was

Table 3 Distribution of implants by diameter and location $(n=223)$

\begin{tabular}{llllll}
\hline Dia. $(\mathrm{mm})$ & $\begin{array}{l}\text { Maxilla } \\
\text { anterior }\end{array}$ & $\begin{array}{l}\text { Maxilla } \\
\text { posterior }\end{array}$ & $\begin{array}{l}\text { Mandible } \\
\text { anterior }\end{array}$ & $\begin{array}{l}\text { Mandible } \\
\text { posterior }\end{array}$ & Total \\
\hline 3.5 & 1 & 2 & 15 & 14 & 32 \\
4.0 & 0 & 0 & 13 & 17 & 30 \\
4.1 & 1 & 20 & 19 & 118 & 158 \\
4.8 & 0 & 0 & 0 & 3 & 3 \\
Total & 2 & 22 & 47 & 152 & 223 \\
\hline
\end{tabular}


Table 4 Distribution of implants by length and location $(n=223)$

\begin{tabular}{llllll}
\hline Dia. $(\mathrm{mm})$ & $\begin{array}{l}\text { Maxilla } \\
\text { anterior }\end{array}$ & $\begin{array}{l}\text { Maxilla } \\
\text { posterior }\end{array}$ & $\begin{array}{l}\text { Mandible } \\
\text { anterior }\end{array}$ & $\begin{array}{l}\text { Mandible } \\
\text { posterior }\end{array}$ & Total \\
\hline 8 & 0 & 8 & 3 & 8 & 19 \\
10 & 0 & 5 & 9 & 73 & 87 \\
11 & 1 & 0 & 1 & 6 & 8 \\
12 & 1 & 9 & 7 & 44 & 61 \\
14 & 0 & 0 & 13 & 13 & 26 \\
17 & 0 & 0 & 11 & 7 & 18 \\
20 & 0 & 0 & 3 & 1 & 4 \\
Total & 2 & 22 & 47 & 152 & 223 \\
\hline
\end{tabular}

determined. The results were considered statistically significant at $p<0.05$.

\section{Results}

\section{Patient cohort}

A total of 92 patients (38 men, 54 women; mean age 54.3 years, range 20-78) received implant-supported prostheses (at the seven private practices) between 1984 and 1990. The distribution of patients by age and gender is presented in Table 1. Fifty-seven patients (140 implants) were considered dropouts due to the fact that no data were obtained at the endpoint, but 25 years had passed since the prosthetic treatment delivery of one dropout patient (with four implants). The Kaplan-Meier estimate shows the censorings (Fig. 1), and they present unbiased throughout the observation period. The dropout reasons for 42 patients were illness, moved away, and not showing up for check-ups; another 15 patients had passed away before the present analysis.

\section{Implant diameter, length, and location}

A total of 223 implants were placed in 15 fully edentulous patients and 77 partially edentulous patients. The distributions of implants by diameter, length, and location are presented in Tables 2, 3, and 4. Twenty-four implants were placed in the maxilla (10.8\%), and 199 implants were placed in the mandible (89.2\%). Only two implants were applied to the maxillary anterior region, whereas 152 implants (68.2\%) were applied to the mandibular posterior region (Tables 2 and 3). Regarding the sizes of the implants, $4.1-\mathrm{mm}$ dia. and $10-\mathrm{mm}$ length were the most frequently used implant dimensions (70.9 and 39\%, respectively).

\section{Additional surgery}

Four implants of one patient were inserted into the reconstructed mandible with iliac bone, due to an ameloblastoma. Additional soft tissue managements were applied to 96 implants. Free gingival graft was used for 86 implants, and frenectomy and vestibular extension were applied to 15 and 13 implants, respectively.

\section{Cumulative survival rate and biological complications}

Sixteen implants were lost during the observation period. The Kaplan-Meier cumulative survival rates were 97.4, 95.4, and $89.8 \%$ at 10,15 , and 25 years after the prosthesis setting, respectively (Fig. 1). After stepwise backward selection, implant position in the mandibular vs. the maxilla showed the significant difference in the cumulative survival rate (Table 5, Fig. 2c). The gender, implant type, additional soft tissue management, and width of keratinized mucosa did not provide significant differences with respect to the survival of the evaluated implants in this study (Fig. 2a, b, d, and e). The reasons for late failure were peri-implant infection (14 implants) and unknown (two implants).

A total of 48 implants were eventually accompanied by a peri-implant infection: the cumulative incidence of peri-implantitis was $9.5,15.3,21.0$, and $27.9 \%$ at 5 , 10,15 , and 25 years after the prosthesis delivery, respectively (Fig. 3). After stepwise backward selection, the gender, implant type, and width of keratinized mucosa showed the significant difference in the cumulative survival rate (Table 6 , Fig. $4 a$, b, and e). The difference in implant position and additional soft tissue management did not result in significant differences with respect to the cumulative incidence of peri-implantitis (Fig. 4c, d).

Table 5 Cox regression analyses for implant survival

\begin{tabular}{llll}
\hline & Hazard ratio & $95 \%$ confidence interval & $p$ value \\
\hline Gender (male) & 1.99 & $0.538 \sim 8.201$ & 0.3018 \\
Implant type (TPS) & 2.86 & $0.579 \sim 13.626$ & 0.1897 \\
Implant position (maxilla to mandibular/anterior) & 40.09 & $4.062 \sim 994.751$ & 0.0012 \\
Implant position (maxilla to mandibular/posterior) & 18.69 & $3.127 \sim 155.409$ & 0.0013 \\
Implant position (mandibular/anterior to mandibular/posterior) & 0.47 & $0.022 \sim 3.912$ & 0.5024 \\
Additional soft tissue management (yes) & 1.64 & $0.290 \sim 12.695$ & 0.5808 \\
Width of keratinized mucosa $(>2 \mathrm{~mm})$ & 0.78 & $0.166 \sim 3.294$ & 0.7365 \\
\hline
\end{tabular}




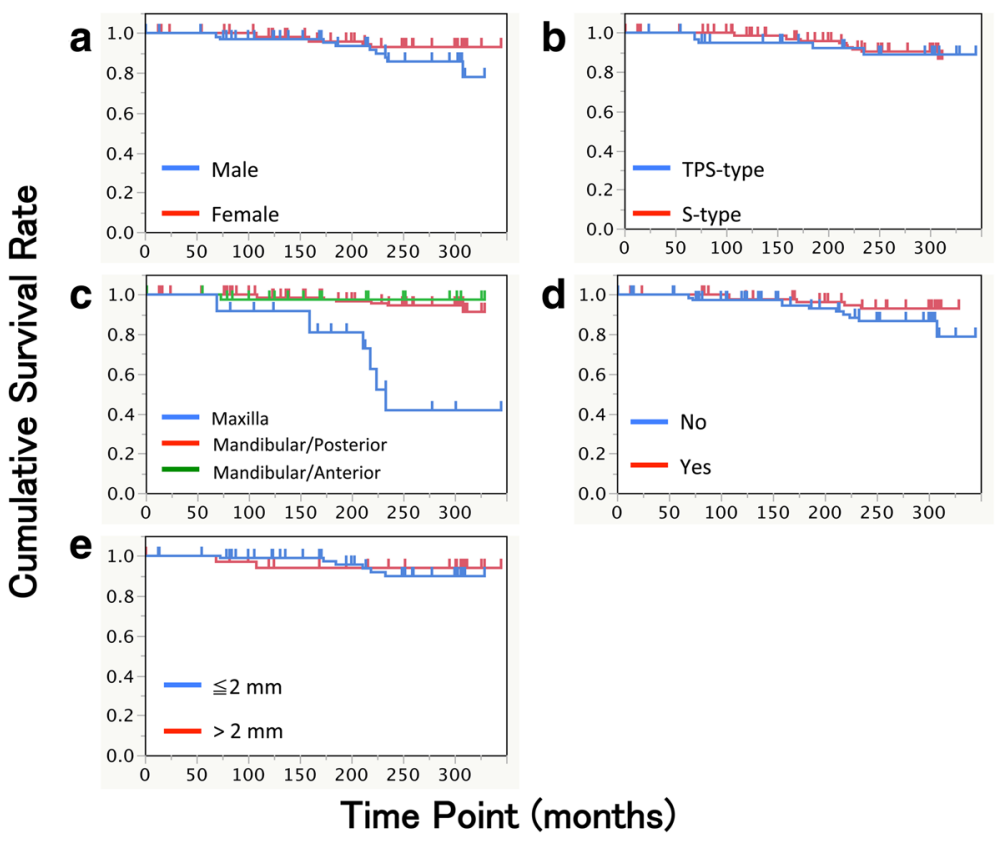

Fig. 2 Kaplan-Meier cumulative survival rates by a gender $(p=0.1049)$, $\mathbf{b}$ implant type $(p=0.6259)$, $\mathbf{c}$ implant position $(p<0.0001)$, $\mathbf{d}$ presence of additional soft tissue management $(p=0.1149)$, and $\mathbf{e}$ width of keratinized mucosa around implant $(p=0.7132)$. Log rank test was used for assessing statistical significance

\section{Cumulative survival rate of mechanical complication-free prostheses}

A total of 106 prostheses were applied to 92 patients. Nine prostheses were single crowns, 17 prostheses were implant-supported overdentures, and the other 80 prostheses were multiunit fixed partial dentures. Thirty-seven of the multiunit fixed partial dentures were splinted with natural teeth as an abutment (i.e., tooth implant-supported fixed prostheses). With respect to the materials of the occlusal surface, 21 of the fixed prostheses were veneered with porcelain, and the other 68 were made from dental alloys (Au-Pt or $\mathrm{Au}-\mathrm{Ag}-\mathrm{Pd}$ alloys).

The Kaplan-Meier cumulative survival rate of mechanical complication-free prostheses was $74.9,68.8$, and $56.4 \%$ at

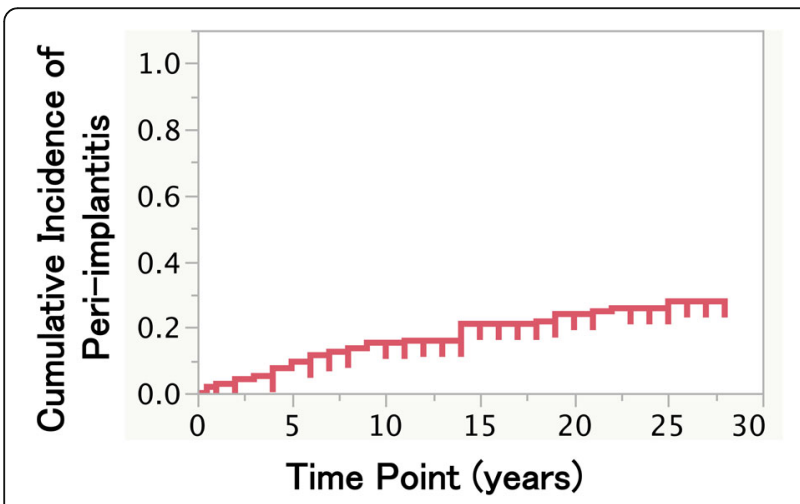

Fig. 3 Cumulative incidence of peri-implantitis
10, 15, and 25 years (Fig. 5). The gender difference did not result in a significant difference with respect to the rate of mechanical complication-free prosthesis, but the difference in the type of prosthesis did (Table 7, Fig. 6a, b). For 11 of the 37 tooth implant-supported prostheses, the abutment teeth were extracted due to caries, periodontitis, or root fracture during the observation period. Regarding the implant-supported overdentures, the following mechanical complications were observed: the total number of relinings was 22 times; that of artificial tooth replacement was 17; attachment replacements were performed 15 times; bar

Table 6 Cox regression analyses for cumulative incidence of peri-implantitis

\begin{tabular}{|c|c|c|c|}
\hline & Hazard ratio & $\begin{array}{l}95 \% \text { confidence } \\
\text { interval }\end{array}$ & $p$ value \\
\hline Gender (male) & 2.38 & $1.138 \sim 5.362$ & 0.0208 \\
\hline Implant type (TPS) & 4.35 & $1.897 \sim 9.941$ & 0.0006 \\
\hline $\begin{array}{l}\text { Implant position } \\
\text { (maxilla to mandibular/anterior) }\end{array}$ & 6.08 & $1.384 \sim 24.436$ & 0.0188 \\
\hline $\begin{array}{l}\text { Implant position } \\
\text { (maxilla to mandibular/posterior) }\end{array}$ & 3.45 & $0.903 \sim 11.111$ & 0.0679 \\
\hline $\begin{array}{l}\text { Implant position } \\
\text { (mandibular/anterior } \\
\text { to mandibular/posterior) }\end{array}$ & 0.57 & $0.207 \sim 1.442$ & 0.2370 \\
\hline $\begin{array}{l}\text { Additional soft tissue } \\
\text { management (yes) }\end{array}$ & 1.18 & $0.535 \sim 2.714$ & 0.6826 \\
\hline $\begin{array}{l}\text { Width of keratinized } \\
\text { mucosa }(>2 \mathrm{~mm})\end{array}$ & 0.24 & $0.094 \sim 0.559$ & 0.0006 \\
\hline
\end{tabular}




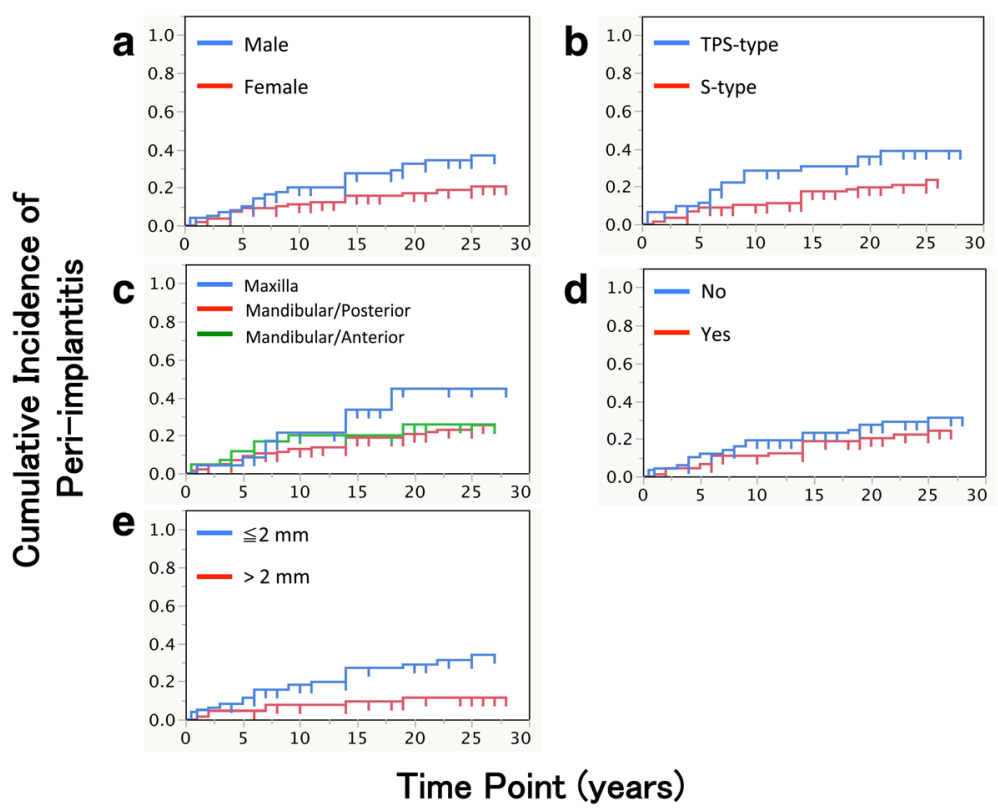

Fig. 4 Cumulative incidence of peri-implantitis by a gender $(p=0.0221)$, $\mathbf{b}$ implant type $(p=0.0128)$, $\mathbf{c}$ implant position $(p=0.2470)$, d presence of additional soft tissue management $(p=0.2488)$, and e width of keratinized mucosa around implant $(p=0.0045)$. Log rank test was used for assessing statistical significance

fractures were observed in three cases, and screw loosening occurred twice.

\section{Discussion}

Although all implants used in this study were withdrawn from the market about 20 years before, the longitudinal clinical outcomes over decades will help to better understand potential factors leading to implant failure or complications and assess the safe and predictable use of dental implant. Our analyses revealed a 25-year cumulative survival rate of $89.8 \%$ after the prosthesis setting, which seems comparable to the result of a recent study [7]. Although approx. $62 \%$ of the patients and implants in our original cohort dropped out during the follow-up

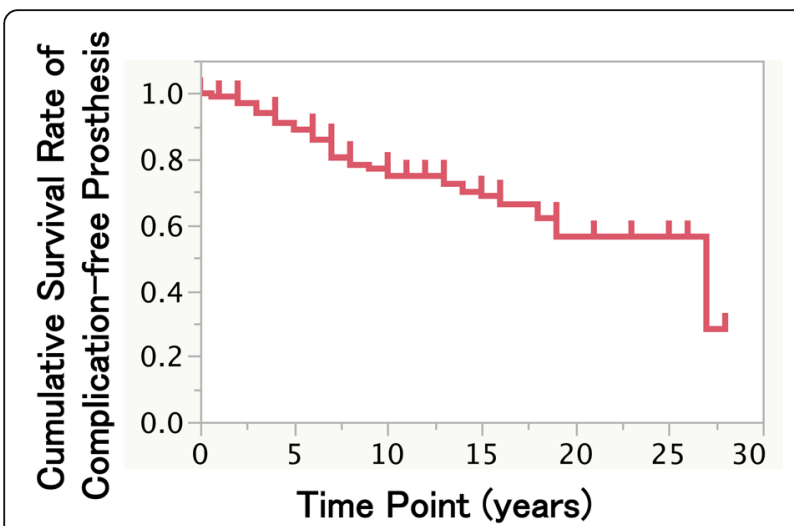

Fig. 5 Kaplan-Meier cumulative survival rate of complication-free prostheses at 10,15, and 25 years after the prosthesis setting period, according to Table 1, a majority of patients who underwent implant treatment were middle- and old-aged (82.6\% of the patients were $40-69$ years old) and thus some of the patients could not continue maintenance for varying reasons over a 25 -year follow-up. The other 38\% of the patients are healthy and likely to visit their dentists for maintenance, and they were included in the 25-year cumulative survival rate [7]. Therefore, the true long-term survival rate might have been lower than we reported herein due to bias from the patients who dropped out.

In addition, only four implants of one patient were inserted into a re-constructed site from the iliac bone; no other bone augmentation procedure such as bone graft, guided bone regeneration (GBR), and sinus floor elevation were conducted. The principle of guided tissue regeneration (GTR) was introduced in 1982 [10], and GBR was introduced in 1988 [11]. The technique of sinus floor elevation was initially introduced in 1980 [12]. These complex augmentation procedures had not been common at that time [2], especially in private practices in Japan, and thus, they were not used for any of the patients in the present study. There is thus some degree of bias regarding the numbers of implant and the lengths of the implants according to the implant position. The number of implants applied to the maxilla anterior region was only two, since getting the esthetic result with implant prostheses was uncertain in those days. And the number of implants under $10 \mathrm{~mm}$ long was greater at posterior sites compared to anterior sites due to the sinus and inferior alveolar nerve. 
Table $\mathbf{7}$ Cox regression analyses for cumulative survival rate of complication-free prostheses

\begin{tabular}{llll}
\hline & Hazard ratio & $95 \%$ confidence interval & $p$ value \\
\hline Gender (male) & 1.82 & $0.946 \sim 3.487$ & 0.0725 \\
$\begin{array}{l}\text { Type of prostheses (implant-supported fixed prostheses to } \\
\text { implant-supported overdenture) }\end{array}$ & 0.04 & $0.013 \sim 0.108$ & $<.0001$ \\
$\begin{array}{l}\text { Type of prostheses (implant-supported fixed prostheses to } \\
\text { tooth implant-supported fixed prostheses) }\end{array}$ & 0.13 & $0.047 \sim 0.316$ \\
$\begin{array}{l}\text { Type of prostheses (tooth implant-supported fixed prostheses } \\
\text { to implant-supported over denture) }\end{array}$ & 0.31 & $0.148 \sim 0.654$ & $<.0001$ \\
\hline
\end{tabular}

Peri-implantitis is the major reason for late failure $[13,14]$. The consensus report of the Sixth European Workshop on Periodontology described peri-implant mucositis in approx. $80 \%$ of subjects restored with implant, and peri-implantitis in $28-56 \%$ of subjects [15]. In the present study, the cumulative incidence of peri-implantitis was $9.5,15.3,21.0$, and $27.9 \%$ at 5,10 , 15 , and 25 years after the prosthesis setting, respectively. Derks and Tomasi reported a positive relationship between the incidence of peri-implantitis and the mean function time by performing a meta-regression analysis of a systematic review [16], whereas the current cumulative result shown in Fig. 3 may represent the time course of the peri-implantitis incidence. Interestingly, the incidence of the peri-implantitis increased gradually with time; the rate of increase was approx. $1-1.5 \%$ per year.

Many potential factors associated with the incidence of peri-implantitis were reported $[17,18]$. In the present study, the gender, implant type, and width of keratinized mucosa were identified as risk factors. Regarding gender, Koldsland et al. also reported a male population with overt peri-implantitis [19], whereas Attard and Zarb reported that women experienced more peri-implant bone loss than men [20]. Other studies and reviews reported that gender had no effect on peri-implantitis $[21,22]$. Some other gender-related factors might affect the results.

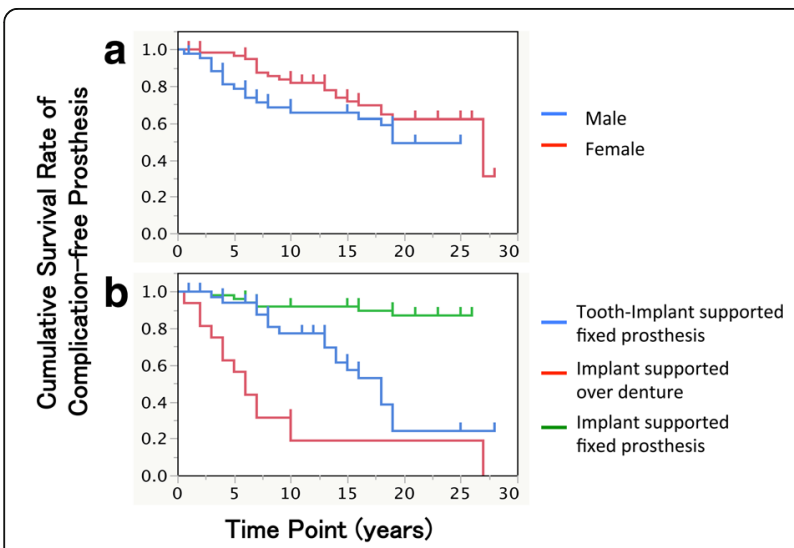

Fig. 6 Cumulative survival rate of complication-free prostheses by a gender $(p=0.1220)$ and $\mathbf{b}$ type of prostheses $(p<0.0001)$. Log rank test was used for assessing statistical significance
Regarding implant type, a difference between the S-types and the TPS-types is whether the existence of an abutment connection or not. The TPS-types are one-piece implants, and the S-types are two-piece but one-stage implants. Duda et al. reported that one-piece implants showed more marginal bone loss than two-piece implants [23]. In addition, a TPS surface is classified as "rough" surface when the surface roughness is more than $2 \mu \mathrm{m}$ (Sa $>2 \mu \mathrm{m})$ [24]. Teughels et al. reported that a transmucosal implant surface with higher surface roughness facilitates biofilm formation [25] and thus TPS-type implants showed a higher incidence of peri-implantitis compared to the S-type.

Regarding the width of keratinized mucosa, many studies and a review have indicated that the presence of a sufficient width of keratinized mucosa is necessary for maintaining healthy peri-implants [26-29]. In the present study, when $2 \mathrm{~mm}$ of keratinized mucosa was used as the adequate width, the $p$ value was 0.053 (data not shown). This also showed the tendency of the availability of keratinized mucosa around implants, and it may indicate that at least $2 \mathrm{~mm}$ of keratinized mucosa is preferable for the long-term success and survival of implants.

Our analysis showed that 16 of 223 implants were lost during the observation period. Among the six factors examined, only the implant position affected the cumulative implant survival rate and the main reason for implant failure was peri-implantitis (14/16 failed implants). However, the implant position did not affect the incidence of peri-implantitis. Compared to the mandible, the bone quality of the maxilla is lower [30] and the loading force is tilted to the implant axis. These factors might have acted as an exacerbating factor of peri-implantitis, resulting in the lower survival rate of the implants in the maxilla compared to the mandible.

Prosthetic complications occur due to the accumulation of mechanical damage to the implant, implant components, and supra-structures, resulting in the need for repairs and reconstructions of the implant prostheses, which may require time-consuming procedures and additional financial resources. The present investigation was a retrospective and multicenter study, and there were many differences in design patterns, materials, connections, and the attachment of supra-structures. It was therefore 
difficult to subdivide and review the factors that may affect the prosthetic survival rate, and only gender and type of prosthesis could be analyzed in this study.

The implant-supported fixed prostheses showed the highest complication-free survival rate in our study. It was reported that the veneering material's chipping/ fracture is the most common type of prosthetic complication for fixed prostheses [31, 32]. Pjetursson et al. reported that veneer fracture was observed in $13.5 \%$ of fixed prostheses after at least 5-year functioning [33]. In the present study, approx. $76 \%$ of the fixed prostheses were not veneered (metal occlusal surface), resulting in the lower complication rate after 25 years of functioning.

We also observed that the tooth-implant-supported prostheses had a lower complication-free rate than implant-supported fixed prostheses due to caries, periodontitis, or the root fracture of abutment teeth. Lang et al. reported that the survival rates of tooth implantsupported fixed partial dentures were $94.1 \%$ after 5 years and $77.8 \%$ after 10 years of functioning [31], and these results were almost the same as ours $(93.9 \%$ after 5 years' and $77.2 \%$ after 10 years' functioning). Taking our results and those of Lang et al. into account, it appears that prosthetic complications of tooth implant-supported prostheses start arising after 7 years post-setting and then increase with time.

The implant-supported overdentures showed the lowest complication-free rate among the three implant types in the present study, due to the wear or fracture of artificial teeth, attachment fracture, and relines. Compared to another retrospective study of conventional complete dentures (without implant support) [34], our complication-free rate was higher and there was a difference in terms of the incidence of artificial tooth problems. That study showed a $<10 \%$ of incidence of artificial tooth problems during the first 5 years postsetting. The rigid support provided by an implant might have enhanced the loss, wear, and fracture of artificial teeth in our patients.

\section{Conclusions}

In conclusion, our analyses revealed a cumulative survival rate of $89.8 \%$ of TPS-surface implants with at least 25 years of functioning. The survival rate of maxillary positioned implants was significantly lower than that of mandibulary positioned implants. The patient gender, implant location, and width of keratinized mucosa affected the rate of peri-implantitis, resulting in late failure. Implant-supported overdentures were frequently repaired compared to the fixed prostheses due to the wear or fracture of artificial teeth, attachment fracture, and relines. Tooth implant-supported prostheses were not beneficial for long term owing to the troubles of abutment tooth.

\section{Authors' contributions}

$\mathrm{TH}, \mathrm{TO}$, and TS initiated and designed the retrospective study and drafted the manuscript including the preparation of figures and tables. TH, TAI, YS, $\mathrm{HM}, \mathrm{NA}, \mathrm{NT}$, and TOI reviewed the medical records and collected the data. All authors revised the manuscript and approved the final manuscript.

\section{Competing interests}

Tadashi Horikawa, Tetsurou Odatsu, Takatoshi Itoh, Yoshiki Soejima, Hutoshi Morinaga, Naruyoshi Abe, Naoyuki Tsuchiya, Toshikazu lijima, and Takashi Sawase declare that they have no competing interests.

\section{Publisher's Note}

Springer Nature remains neutral with regard to jurisdictional claims in published maps and institutional affiliations.

\section{Author details}

${ }^{1}$ Kyushu Implant Research Group, 4-14 Kokaihonmachi, Chuo-ku, Kumamoto 860-0851, Japan. ${ }^{2}$ Department of Applied Prosthodontics, Graduate School of Biomedical Sciences, Nagasaki University, 1-7-1 Sakamoto, Nagasaki 852-8588, Japan.

Received: 26 April 2017 Accepted: 28 August 2017

Published online: 05 September 2017

\section{References}

1. Brånemark PI, Adell R, Breine U, Hansson BO, Lindström J, Ohlsson A. Intraosseous anchorage of dental prostheses. I. Experimental studies. Scand J Plast Reconstr Surg. 1969;3:81-100.

2. Buser D, Sennerby L, De Bruyn H. Modern implant dentistry based on osseointegration: 50 years of progress, current trends and open questions. Periodontol. 2017;73:7-21.

3. Ekelund JA, Lindquist LW, Carlsson GE, Jemt T. Implant treatment in the edentulous mandible: a prospective study on Brånemark system implants over more than 20 years. Int J Prosthodont. 2003;16:602-8.

4. Lekholm U, Gröndahl K, Jemt T. Outcome of oral implant treatment in partially edentulous jaws followed 20 years in clinical function. Clin Implant Dent Relat Res. 2006;8:178-86.

5. Astrand P, Ahlqvist J, Gunne J, Nilson H. Implant treatment of patients with edentulous jaws: a 20-year follow-up. Clin Implant Dent Relat Res. 2008;10:207-17.

6. Chappuis V, Buser R, Brägger U, Bornstein MM, Salvi GE, Buser D. Long-term outcomes of dental implants with a titanium plasma-sprayed surface: a 20-year prospective case series study in partially edentulous patients. Clin Implant Dent Relat Res. 2013;15:780-90.

7. Becker ST, Beck-Broichsitter BE, Rossmann CM, Behrens E, Jochens A, Wiltfang J. Long-term survival of Straumann dental implants with TPS surfaces: a retrospective study with a follow-up of 12 to 23 years. Clin Implant Dent Relat Res. 2016;18:480-8.

8. Buser D, Mericske-Stern R, Bernard JP, Behneke A, Behneke N, Hirt HP, Belser UC, Lang NP. Long-term evaluation of non-submerged ITI implants. Part 1: 8-year life table analysis of a prospective multi-center study with 2359 implants. Clin Oral Implants Res. 1997;8:161-72.

9. Lekholm U, Gunne J, Henry P, Higuchi K, Lindén U, Bergström C, van Steenberghe D. Survival of the Brånemark implant in partially edentulous jaws: a 10-year prospective multicenter study. Int J Oral Maxillofac Implants. 1999:14:639-45

10. Nyman S, Lindhe J, Karring T, Rylander H. New attachment following surgical treatment of human periodontal disease. J Clin Periodontol. 1982;9:290-6.

11. Dahlin C, Linde A, Gottlow J, Nyman S. Healing of bone defects by guided tissue regeneration. Plast Reconstr Surg. 1988;81:672-6.

12. Boyne PJ, James RA. Grafting of the maxillary sinus floor with autogenous marrow and bone. J Oral Surg. 1980;38:613-6.

13. Hellem S, Karlsson U, Almfeldt I, Brunell G, Hamp SE, Astrand P. Nonsubmerged implants in the treatment of the edentulous lower jaw: a 5-year prospective longitudinal study of ITI hollow screws. Clin Implant Dent Relat Res. 2001;3:20-9.

14. Roos-Jansåker AM, Lindahl $C$, Renvert $H$, Renvert S. Nine- to fourteen-year follow-up of implant treatment. Part II: presence of peri-implant lesions. J Clin Periodontol. 2006;33:290-5. 
15. Lindhe J, Meyle J, Group D European Workshop on Periodontology. Periimplant diseases: Consensus Report of the Sixth European Workshop on Periodontology. J Clin Periodontol. 2008;35(Suppl 8):282-5.

16. Derks J, Tomasi C. Peri-implant health and disease. A systematic review of current epidemiology. J Clin Periodontol. 2015;42(Suppl 16):S158-71.

17. Sgolastra F, Petrucci A, Severino M, Gatto R, Monaco A. Periodontitis, implant loss and peri-implantitis. A meta-analysis. Clin Oral Implants Res. 2015;26:e8-16.

18. Stacchi C, Berton F, Perinetti G, Frassetto A, Lombardi T, Khoury A, Andolsek F, Di Lenarda R. Risk factors for peri-implantitis: effect of history of periodontal disease and smoking habits. A systematic review and metaanalysis. J Oral Maxillofac Res. 2016;7:e3.

19. Koldsland OC, Scheie AA, Aass AM. The association between selected risk indicators and severity of peri-implantitis using mixed model analyses. J Clin Periodontol. 2011:38:285-92.

20. Attard NJ, Zarb GA. Long-term treatment outcomes in edentulous patients with implant-fixed prostheses: the Toronto study. Int J Prosthodont. 2004;17:417-24.

21. Geckili O, Mumcu E, Bilhan H. The effect of maximum bite force, implant number, and attachment type on marginal bone loss around implants supporting mandibular overdentures: a retrospective study. Clin Implant Dent Relat Res. 2012;14(Suppl 1):e91-7.

22. Renvert S, Aghazadeh A, Hallström H, Persson GR. Factors related to periimplantitis - a retrospective study. Clin Oral Implants Res. 2014;25:522-9.

23. Duda M, Matalon S, Lewinstein I, Harel N, Block J, Ormianer Z. One piece immediately loading implants versus 1 piece or 2 pieces delayed: 3 years outcome. Implant Dent. 2016;25:109-13.

24. Wennerberg A, Albrektsson T. Effects of titanium surface topography on bone integration: a systematic review. Clin Oral Implants Res. 2009; 20(Suppl 4):172-84.

25. Teughels W, Van Assche N, Sliepen I, Quirynen M. Effect of material characteristics and/or surface topography on biofilm development. Clin Oral Implants Res. 2006;17(Suppl 2):68-81.

26. Brito C, Tenenbaum HC, Wong BK, Schmitt C, Nogueira-Filho G. Is keratinized mucosa indispensable to maintain peri-implant health? A systematic review of the literature. J Biomed Mater Res B Appl Biomater. 2014:102:643-50

27. Ferreira CF, Buttendorf AR, de Souza JG, Dalago H, Guenther SF, Bianchini MA. Prevalence of peri-implant diseases: analyses of associated factors. Eur J Prosthodont Restor Dent. 2015;23:199-206.

28. Ladwein C, Schmelzeisen R, Nelson K, Fluegge TV, Fretwurst T. Is the presence of keratinized mucosa associated with periimplant tissue health? A clinical cross-sectional analysis. Int J Implant Dent. 2015;1(1):11.

29. Canullo L, Peñarrocha-Oltra D, Covani U, Botticelli D, Serino G, Penarrocha M. Clinical and microbiological findings in patients with peri-implantitis: a cross-sectional study. Clin Oral Implants Res. 2016;27:376-82.

30. Ko YC, Huang HL, Shen YW, Cai JY, Fuh LJ, Hsu JT. Variations in crestal cortical bone thickness at dental implant sites in different regions of the jawbone. Clin Implant Dent Relat Res. 2017; doi: 10.1111/cid.12468.

31. Lang NP, Pjetursson BE, Tan K, Brägger U, Egger M, Zwahlen M. A systematic review of the survival and complication rates of fixed partial dentures (FPDs) after an observation period of at least 5 years. II. Combined tooth implant-supported FPDs. Clin Oral Implants Res. 2004;15:643-53.

32. Aglietta M, Siciliano VI, Zwahlen M, Brägger U, Pjetursson BE, Lang NP, Salvi GE. A systematic review of the survival and complication rates of implant supported fixed dental prostheses with cantilever extensions after an observation period of at least 5 years. Clin Oral Implants Res. 2009:20:441-51.

33. Pjetursson $B E$, Thoma $D$, Jung $R$, Zwahlen $M$, Zembic A. A systematic review of the survival and complication rates of implant-supported fixed dental prostheses (FDPs) after a mean observation period of at least 5 years. Clin Oral Implants Res. 2012;23(Suppl 6):22-38.

34. Dorner S, Zeman F, Koller M, Lang R, Handel G, Behr M. Clinical performance of complete dentures: a retrospective study. Int J Prosthodont. 2010;23:410-7.

\section{Submit your manuscript to a SpringerOpen ${ }^{\circ}$ journal and benefit from:}

- Convenient online submission

- Rigorous peer review

Open access: articles freely available online

- High visibility within the field

- Retaining the copyright to your article

Submit your next manuscript at $\gg$ springeropen.com 